\title{
VIOLÊNCIAS ÀS PESSOAS EM SITUAÇÃO DE RUA: O DIREITO FUNDAMENTAL À SEGURANÇA EM XEQUE
}

\author{
Luciano Roberto Gulart Cabral Júnior* \\ Eder Dion de Paula Costa**
}

\begin{abstract}
RESUMO
Objetiva-se neste artigo analisar as violências que acometem as pessoas em situação de rua e sua relação com o direito fundamental à segurança. Inicialmente, abordar-se-á a fragilidade social que afeta as pessoas em situação de rua, de modo a esboçar um panorama das idiossincrasias que lhes são atinentes. Em seguida, dialogar-se-á entre as modalidades de violências que atingem a população em situação de rua e o direito fundamental à segurança. A problemática projeta como o direito fundamental à segurança é, de fato, essencial no combate às violências para se trilhar rumo a garantir às pessoas em situação de rua, em última instância, a dignidade humana, fundamento da República Federativa do Brasil. Nesse contexto que se realiza a presente pesquisa qualitativa, através do método de abordagem dedutivo e do método de procedimento monográfico, com base na bibliografia e no conteúdo legislativo sobre o tema.
\end{abstract}

PALAVRAS-CHAVE: Direito fundamental à segurança. População em situação de rua. Violências.

\begin{abstract}
The objective in this article is to analyze the violences that affect homeless people and their relation to the fundamental right to safety. Initially, it will be approached to social fragility that affects homeless people, in order to draw a picture of the idiosyncrasies that they are relating. Then, it will be dialogued between the forms of
\end{abstract}

\footnotetext{
* Mestrando em Direito e Justiça Social no Programa de Pós-Graduação em Direito da Universidade Federal do Rio Grande - FURG.

E-mail: lucianocabraljunior@hotmail.com

** Professor no Programa de Mestrado em Direito e Justiça Social e do Curso de Graduação em Direito da Faculdade de Direito da Universidade Federal do Rio Grande - FURG. Doutor em Direito pela Universidade Federal do Paraná.

E-mail: ederdion@gmail.com
} 
violences that affect the homeless people and the fundamental right to safety. The problematic projects as the fundamental right to safety is, indeed, essential in the fight against violences to walk towards ensuring the homeless people, in the last instance, the human dignity, foundation of the Federative Republic of Brazil. In this context it is done this qualitative research, through the deductive method of approach and the monographic method of procedure, based on the literature and legislative content on the subject.

KEYWORDS: Fundamental right to safety. Homeless people. Violences.

\section{INTRODUÇÃO}

Um tema que preocupa a sociedade brasileira é a violência. Cotidianamente várias formas de violência vitimizam indivíduos e a sociedade em geral. A questão torna-se mais preocupante, todavia, diante de grupos vítimas dos processos socioeconômicos excludentes, como a população em situação de rua. A segurança, direito fundamental que, em razão disso, assume importância ímpar no ordenamento jurídico brasileiro, é o núcleo de onde emana um dos pilares que propicia uma apreciação das violências às pessoas em situação de rua.

Com base em uma pesquisa qualitativa, tendo como método de abordagem o dedutivo, através de pesquisa bibliográfica e legislativa sobre o tema, utilizando-se do método de procedimento monográfico (LAKATOS; MARCONI, 2012, p. 110), objetiva-se analisar, então, as violências que acometem as pessoas em situação de rua e sua relação com o direito fundamental à segurança. A relevância jurídico-social remonta aos percalços aos quais a população em situação de rua é diuturnamente vítima, pressupondo que se perquira a forma pela qual as violências lhe tocam, com o escopo de propiciar que o direito fundamental à segurança seja devidamente arquitetado e posto em ação para assegurar a sua efetiva concretização.

\section{PESSOAS EM SITUAÇÃo de RUA: UM PANORAMA GERAL}

O Decreto $\mathrm{n}^{0} 7.053$, de 23 de dezembro de 2009, que "institui a Política Nacional para a População em Situação de Rua e seu 
Comitê Intersetorial de Acompanhamento e Monitoramento, e dá outras providências", dispõe, no seu artigo $1^{\circ}$, parágrafo único, sobre o que são as pessoas em situação de rua:

Para fins deste Decreto, considera-se população em situação de rua o grupo populacional heterogêneo que possui em comum a pobreza extrema, os vínculos familiares interrompidos ou fragilizados e a inexistência de moradia convencional regular, e que utiliza os logradouros públicos e as áreas degradadas como espaço de moradia e de sustento, de forma temporária ou permanente, bem como as unidades de acolhimento para pernoite temporário ou como moradia provisória.

Com efeito, sem adentrar nas possíveis críticas ao conceito atribuído pelo Decreto supracitado, as pessoas em situação de rua ${ }^{1}$ detêm baixa renda, habitando temporária ou permanentemente logradouros públicos (como praças e viadutos), áreas degradadas, ou pernoitando em albergues públicos. Esses espaços constituem o habitat de convívio de dita população. (SIMÕES JÚNIOR, 1992, p. 17)

No Brasil, a Pesquisa Nacional sobre a População em Situação de Rua identificou, entre agosto de 2007 e março de 2008, 31.922 pessoas em situação de rua nas 71 cidades pesquisadas (BRASIL, 2009). Certamente, portanto, o número de pessoas brasileiras em situação de rua supera o índice constatado.

Sabe-se que o coletivo de pessoas em situação de rua é amplo, múltiplo e mutável, e que varia de acordo com o momento político e socioeconômico do país e região em que se estuda tal fenômeno. Sabe-se ainda que a problemática social da existência de um grande número de pessoas em situação de rua não atinge somente aos adultos do gênero masculino. Crianças, mulheres, idosos e muitas vezes famílias inteiras fazem parte dessa realidade, social e historicamente construída, em um cenário mundial marcado pela injustiça social. (ALCANTARA; ABREU; FARIAS, 2015, p. 142)

\footnotetext{
${ }^{1}$ A terminologia "população em situação de rua" ou "pessoas em situação de rua" é mais adequada do que a usual "moradores de rua" ou similares, seja porque a rua não pode ser considerada uma moradia, seja porque ninguém é de rua assim como ninguém é de casa ou de apartamento (isto é, a rua é um estágio - situação - que merece ser superada), seja porque ressalta a natureza de pessoa humana desse grupo social.
} 
Criticamente, entretanto em compasso com a realidade, constituem as pessoas em situação de rua uma parcela da população que, embora seja permita a presença física no território do Estado, é excluída dos sistemas prestacionais jurídicos, econômicos, políticos, educacionais, restando-lhes um modelo de subintegração (MÜLLER, 2003, p. 91). São "estanhos que não participam do espetáculo social", dotadas de características que a sociedade não reconhece como socialmente integrantes, restando-lhes a negação de parte constitutiva social (VALENCIO, 2008, p. 559).

É indissociável se apreciar o fenômeno em questão com a realidade do modo capitalista de produção - a busca desenfreada pela acumulação de capital, associada ao individualismo exacerbado e à visão de um Estado não interventor, de acordo com a matiz liberal, onde o próprio mercado seria capaz de promover a justiça social, não é compatível, na atualidade brasileira, com uma luta que gere resultados positivos às pessoas em situação de rua. Ademais, elas situam-se, geralmente, em grandes centros urbanos, sendo estigmatizadas. Há uma tendência à naturalização dessa situação, que desencadeia a inexpressividade de dados e informações científicas sobre as pessoas que a enfrenta e a formulação de políticas públicas inócuas para combatê-la. (SILVA, M., 2006, p. 95)

E é justamente nas políticas sociais que se nota como é conferida uma "cidadania invertida" (FLEURY, 1994, p. 108-109) à população em situação de rua, porquanto a proteção social mormente em decorrência da ótica que vislumbra no mercado o principal instrumento idôneo à satisfação das demandas sociais - que é oferecida enfatiza o individualismo e a liberdade justificados em uma igualdade de oportunidades (que é sinônimo, em tal conjuntura, de igualdade social). A intervenção estatal, assim, é tida como medida suplementar que traz consigo a natureza compensatória e discriminatória, destinada a agrupamentos incapazes de inserção adequada no mercado. Para a consecução de um benefício assistencial estatal se exige a comprovação individual da dita incapacidade, o que repercute na consolidação de um benefício concedido em razão do "insucesso" pessoal perante a esfera social.

Agregando-se a isso, as políticas sociais para a população em situação de rua enfrentam barreiras, entre as quais se mencionam: a dificuldade de se pesquisar, mapear e conhecer detalhadamente tais 
pessoas; a dificuldade de informá-las sobre os seus direitos, porque geralmente nômades; a inexpressividade da representação política ou da participação direta das pessoas em situação de rua nos espaços públicos; o caráter assistencialista das políticas sociais que lhes são destinadas; e a proximidade nítida do Governo Federal de Temer com o neoliberalismo (CABRAL JÚNIOR; COSTA, 2016, p. 239).

As pessoas em situação de rua, em suma, estão inseridas, na dicção de B. Santos (2003, p. 25), em uma sociedade incivil, haja vista que não gozam de um nível elevado de inclusão social, desfrutando completamente dos direitos previstos (como no caso da "sociedade civil íntima"), nem ao menos de um nível moderado ou baixo de inclusão social, com um escasso acesso a direitos (como no caso da "sociedade civil estranha"). Ocupam, isso sim, um círculo exterior, o mais distante do Estado, sendo totalmente excluídos e quase que completamente invisíveis, não possuindo, na prática, quaisquer direitos.

\section{AS VIOLÊNCIAS E A SITUAÇÃO DE RUA}

Convive-se, no cotidiano hodierno brasileiro, tão expressivamente com as violências que é estruturado um modo de viver mais em função delas do que as encarando circunstancialmente (ODALIA, 2006, p. 9), considerando-se como um dos problemas sociais e políticos de necessária busca de resolução na atualidade (HERNÁNDEZ, 2002, p. 58). A calamidade da segurança torna os indivíduos vítimas de uma analogia às avessas do sistema panóptico, de Bentham (2008, p. 20-23), cujo efeito mais marcante é "induzir o detento a um estado consciente e permanente de visibilidade que assegura o funcionamento automático do poder" (FOUCAULT, 1999, p. 166). Quer-se dizer que o espaço público (e o privado também) tornou-se um ambiente de constante luta pela segurança e contra as violências, disseminando uma sensação generalizada de perseguição ou espiamento geral em face de pessoas dispostas a cometerem atos de violência. Aliás,

hoje, a arquitetura perde seu sabor pela vida exterior, interioriza-se, e o que se busca, desesperadamente, é a segurança e a defesa.

Defendemo-nos de tudo. Os espaços são fechados, a casa é projetada 
para dentro de si mesma, o exterior é abandonado, pois é o perigo a ser evitado [...] A nova arquitetura preocupa-se em assegurar, para os moradores de uma residência, a segurança de um caramujo ou de uma tartaruga. (ODALIA, 2006, p. 10-11)

Justamente nesse cenário que a morada serve muito mais como proteção do que outrora, investindo os indivíduos na construção de verdadeiras fortalezas em torno de si mesmos. Tais castelos individuais se, por um lado, retratam o isolamento social típico da área urbana, por outro ainda não se desprenderam da função protetiva que fornece aos moradores. Daí porque as pessoas em situação de rua, por evidente, são privadas de um ambiente certo e estável para a sua autoproteção.

Porém, é evidente que esse lado da violência reflete especificamente a violência física - uma modalidade de violência que viola, em primeira instância, a integridade física do indivíduo. Contudo, a violência não se exaure nessa forma de manifestação, podendo vir à tona como violência intrafamiliar, étnica, social, política, criminal, psicológica, entre outras (HERNÁNDEZ, 2002, p. 59). Essa a razão pela qual se refere, mais adequadamente quando se trata das violências em seu conjunto, a "violências", no plural, e não à violência, no singular - apesar de que se esta última concepção for empregada como o gênero das diversas espécies de violência não lhe poderá ser atribuída a mácula da incoerência. Dessa forma,

há violência quando, numa situação de interação, um ou vários atores agem de maneira direta ou indiretamente, maciça ou esparsa, causando danos a uma ou várias pessoas em graus variáveis, seja em sua integridade física, seja em sua integridade moral, em suas posses, ou em suas participações simbólicas ou culturais. (MICHAUD, 1989, p. 10-11).

A violência é um fenômeno complexo que reside no comportamento e seu efeito, dependendo do contexto histórico para que a sua existência e gravidade sejam avaliadas; liga-se inexoravelmente a uma interação humana, ao mesmo tempo que a nega (a negação do outro), despontando usualmente em espaços onde predominam as discriminações, desigualdades e exclusões sociais; possui uma dimensão visível materiais (comportamentos físicos, danos 
materiais), uma dimensão sociocultural latente (espaço psicológico), que a aprecia (aceita, nega, estimula, controla, aprova, reprova), e uma dimensão estrutural, que a relaciona com as estruturas sociais e sistemas culturais. (HERNÁNDEZ, 2002, p. 59-68) Nesse contexto que é acertado se aludir que

a violência a que estão submetidos [os indivíduos em situação de rua] vem de todos os lados, dos agentes de segurança pública, como a polícia e guardas municipais; por parte do Poder Público, por omissão, em muitos casos, pela insuficiência e ineficiência das políticas públicas adotadas, e, por mais contraditório que possa parecer, até mesmo pela ação direta de violação de direitos, como o recolhimento dos pertences dessas pessoas; e da própria sociedade civil, que, respaldada por um sistema de exclusão protagoniza casos absurdos, agredindo verbalmente e fisicamente, e, no extremo, buscando exterminá-los, como os relatos de homicídios e tentativas de homicídios - envenenamento, atear fogo, dentre outros. (MELO, 2016, p. 52)

A população em situação de rua também, assim, também é vítima da violência social. Conquanto toda a violência seja social, a terminologia mencionada é referente especificamente a atos violentos que atingem os grupos populacionais mais desprotegidos e, quando possuem uma maior área de incidência, são - inadequada e hegemonicamente - justificados como imprescindíveis para que a sociedade progrida. (ODALIA, 2006, p. 37)

Oculta-se a violência social a que está submetida a população em situação de rua e, como corolário, as próprias pessoas em situação de rua também jazem em esquecimento em um processo dividido em três etapas: primeiro, desqualificam-se ditas pessoas através de um discurso que as associa à desordem e à insegurança, legitimando a ruptura do contrato social em relação a elas; segundo, a sociedade desvincula-se delas, rejeitando-as e isolando-as, pois improdutivas; e terceiro, elimina-se tal população seja extremamente por intermédio de um extermínio físico, seja pela esterilização, seja pelo genocídio cultural, entre outros. (BURSZTYN, 2003, p. 38-39)

Igualmente, a violência política (ODALIA, 2006, p. 47) afeta sobremaneira a população em situação de rua. Sucintamente, tal modalidade de violência - além de outras idiossincrasias - afeta o aspecto político humano, que se relaciona com as relações sociais 
onde as diferenças são traduzidas em desigualdades em estratificações - o humano político é aquele que possui consciência dos problemas e busca soluções, comandando o seu próprio destino (DEMO, 1996, p. 15-17). Ao se tolher essa capacidade de autodeterminação política, fruto dos parcos meios materiais de subsistência e de consciência crítica que lhe são concedidos, violenta-se a população em situação de rua politicamente. Somado a isso, a violência política se manifesta com a destruição de tudo que possa remeter ao violentado, envolvendo a cultura de um modo geral (MARCONDES FILHO, 1990, p. 11-12).

Por último, inobstante sem a pretensão de extenuar integralmente as modalidades de violência que porventura acometem as pessoas em situação de rua, mister se referir à violência institucionalizada (ODALIA, 2006, p. 24-36) cometida - sim - pelo próprio Estado, que sob o ângulo da violência política, pode ser considerada igualmente como violência do poder ou violência de cima. Dita violência (cuja ideia é mais ampla do que a violência isolada do Estado, porquanto representa a violência do poder como um todo) é utilizada pelo poder para a manutenção da ordem repressiva. (MICHAUD, 1989, p. 22-26)

$\mathrm{E}$, exemplificativamente, verifica-se tal situação quando o Estado se omite no planejamento e na instalação de políticas sociais que surtam efeitos práticos emancipatórios, menosprezando os direitos da população em situação de rua, ou quando atenta as forças públicas preponderantemente às camadas de maior poderio econômico, ou quando se abstém de intervir, desrespeitando o viés social do texto constitucional brasileiro, ou quando, através de uma falsa cultura higienista, inverte a questão social e crê que a mera remoção da população em situação de rua resolve instantaneamente as demais vicissitudes sociais a que está sujeita.

\section{O DIREITO À SEGURANÇA E A SITUAÇÃO DE RUA}

A segurança, mencionada no preâmbulo² da Constituição da

2 Preâmbulo da Constituição da República Federativa do Brasil: "Nós, representantes do povo brasileiro, reunidos em Assembléia Nacional Constituinte para instituir um Estado Democrático, destinado a assegurar o exercício dos direitos sociais e individuais, a liberdade, a segurança, o bem-estar, o desenvolvimento, a 
República Federativa do Brasil, é considerada, conforme a disposição do texto constitucional federal, tanto como direito fundamental individual e coletivo (artigo $5^{\circ}$ ), quanto direito fundamental social $\left(\operatorname{artigo} 6^{\circ}\right)^{3}$, a saber:

Art. $5^{\circ}$, caput, da CF: Todos são iguais perante a lei, sem distinção de qualquer natureza, garantindo-se aos brasileiros e aos estrangeiros residentes no País a inviolabilidade do direito à vida, à liberdade, à igualdade, à segurança e à propriedade [...].

Art. $6^{\circ}$ da CF: São direitos sociais a educação, a saúde, a alimentação, o trabalho, a moradia, o transporte, o lazer, a segurança, a previdência social, a proteção à maternidade e à infância, a assistência aos desamparados, na forma desta Constituição.

A importância da segurança está inserida na normatividade constitucional brasileira. Ultrapassa dessa maneira a mera concepção de senso moral relevante para, como direito fundamental, possibilitar que se exija do Estado tanto a abstenção de condutas que possam prejudicá-lo, quanto a promoção de sua concretização na realidade brasileira. Fica evidente, portanto, que o direito fundamental à segurança é um meio para se resistir ao arbítrio e abusos estatais (BONAVIDES, 2004, p. 615), traduzido em obrigações negativas de comportamentos que lhe violem, e outrossim um poder que permite exigir do Estado uma obrigação positiva (BOBBIO, 1992, p. 21) em prol da segurança.

A Declaração Universal dos Direitos Humanos de 1948 também alude à segurança, ora destacando que os indivíduos

igualdade e a justiça como valores supremos de uma sociedade fraterna, pluralista e sem preconceitos, fundada na harmonia social e comprometida, na ordem interna e internacional, com a solução pacífica das controvérsias, promulgamos, sob a proteção de Deus, a seguinte CONSTITUIÇÃO DA REPÚBLICA FEDERATIVA DO BRASIL."

3 J. A. Silva (2005, p. 437) ainda ressalta que o direito fundamental à segurança pode ser considerado como um conjunto de garantias (garantia fundamental), à medida que possui liame com a proibição e a limitação de situações e almeja assegurar o exercício de outros direitos individuais fundamentais (como a intimidade, a liberdade pessoal, a incolumidade física e moral). 
possuem tal direito, ora vinculando-a a um direito da coletividade, reforçando a colocação do texto constitucional brasileiro a respeito do tema. Observe-se:

Artigo $3^{\circ}$ : Todo indivíduo tem direito à vida, à liberdade e à segurança pessoal.

Artigo $22^{\circ}$ : Toda a pessoa, como membro da sociedade, tem direito à segurança social; e pode legitimamente exigir a satisfação dos direitos econômicos, sociais e culturais indispensáveis, graças ao esforço nacional e à cooperação internacional, de harmonia com a organização e os recursos de cada país.

É nesse sentido que o artigo 144, caput, da Constituição Federal, além de frisar o direito de todos à segurança, salienta o respectivo dever do Estado e a responsabilidade da sociedade, aduzindo que "a segurança pública, dever do Estado, direito e responsabilidade de todos, é exercida para a preservação da ordem pública e da incolumidade das pessoas e do patrimônio”.

Por ordem pública, em linhas gerais, entende-se como um prérequisito funcional da organização do sistema social para a convivência social, a fim de que as pessoas disponham da liberdade cuja única restrição seja aquela impingida pela ordem jurídica. A acepção material da ordem pública diz respeito à situação fática que resulta da disposição harmônica dos elementos que integram uma sociedade, permitindo um funcionamento estável e regular que assegure a liberdade - e, em último estrato, a dignidade da pessoa humana. A acepção formal da ordem pública, por sua vez, concerne ao conjunto de normas que denotam um dever ser regular e estável para a sociedade. (MOREIRA NETO, 1988, p. 139-143) E incolumidade significa ilesividade (LUFT, 2001, p. 383), isenção de perigo ou dano, proteção.

Quanto à oportunidade da garantia em relação ao perigo, a segurança pode ser preventiva (antecipa-se ao perigo) ou repressiva (almeja eliminar ou reduzir o perigo) (MOREIRA NETO, 1988, p. 151). As violências se enquadram nesse perigo que visa a ser prevenido ou reprimido pela segurança, simbolizando um estado de desordem pública, mormente porque viola direitos fundamentais e a dignidade da pessoa humana, estruturantes do Estado constitucional brasileiro. Por isso que 
se as garantias proporcionadas pela segurança pública são eficientes e satisfatórias, tem-se mantida a ordem pública. Se as garantias proporcionadas pela segurança pública são deficientes ou insatisfatórias, tem-se abalada. Se as garantias proporcionadas pela segurança pública são insuficientes, está sacrificada a ordem pública. É, pois, como se vê, uma relação causal. (MOREIRA NETO, 1988, p. 152)

A segurança simboliza um dever de proteção estatal (e de todos) que se vincula aos direitos fundamentais, tutelando-os, e subjaz à ideia de que o Estado detém o monopólio do exercício da força. $\mathrm{Ou}$ seja, a segurança repercute no dever vinculante e juridicamente exigível de o Estado ser o principal responsável na proteção das pessoas contra a violação de seus direitos por quem quer que seja (particulares ou o próprio ente estatal). (SARLET, 2009 , p. 149) A segurança exalta a proteção dos direitos fundamentais como um todo (e não somente à integridade física que um exame apressado pode conduzir, o que abarcaria meramente a violência física) e, por consequência, o direito a segurança é correlacionado a todas as violências.

O reforço infraconstitucional acerca do respeito inexorável do direito à segurança em relação às pessoas em situação de rua é protagonizado pelo Decreto $\mathrm{n}^{\mathrm{o}} 7.053 / 2009$, que prescreve em um de seus objetivos "assegurar o acesso amplo, simplificado e seguro aos serviços e programas que integram as políticas públicas de saúde, educação, previdência, assistência social, moradia, segurança, cultura, esporte, lazer, trabalho e renda" (artigo $7^{\circ}$, inciso I).

Malgrado, a previsão normativa não possui obviamente $o$ condão de, por si só, lidar adequadamente com o problema da violência. Se é verdade que a legislação constitucional e ordinária brasileira pretendem assegurar o direito à segurança às pessoas em situação de rua, tanto mais o é que, na contracorrente, os nefastos prejuízos das violências se tornam muito mais marcantes quando são encarados com normalidade, naturalizando-se no cotidiano social ou negando-se uma solução possível. Isso porque, assim agindo, silencia-se o outro - vítima da violência - e fomenta-se um substrato cultural favorável (ou ao menos despreocupado) com a manifestação da violência (HERNÁNDEZ, 2002, p. 64). Cedendo espaço a estrutura social à violência, a segurança é menosprezada como 
possibilidade e, à míngua de intervenção efetiva, abdica-se de sua concreta incidência.

Um parêntese: o Brasil se caracteriza por conceber uma pobreza integrada, onde os pobres são numerosos. A pobreza, nesse caso, é naturalizada e mais condicionada à determinada região espacial do que a uma questão social de grupos específicos. (PAUGAM, 1999, p. 97-98) Isto é, as violências somam-se à pobreza (que, de certa forma, também é uma violência) e, nesse prisma de desesperança e agonia social de grupos subalternos, aos pobres - e à população em situação de rua - do Brasil resta um clima em que a segurança é sem sombra de dúvidas um dos pilares fundamentais para se projetar uma superação do estágio de violação de direitos.

O maior obstáculo ao combate à cultura da violência é desenraizá-la da sociedade brasileira, construindo-se outros trajetos de relacionamento social em direção a uma sociabilidade solidária. Sem a instauração de práticas sociais que se destinem à erradicação das violências, a realização plena do contrato social no Brasil tornase ainda mais árduo, contribuindo para o reforçamento da concepção de uma "cidadania dilacerada". (SANTOS, J. V. T., 1993, 145-146)

A violência gera somente mais violência, motivo pelo qual a estratégia para combatê-la deve centrar-se na transformação dos ambientes onde ela é reproduzida, modificando o palco social e cultural que a cerca e fecunda. É preciso, então, reconstruir os efeitos humanos, materiais e institucionais acarretados pelas violências, bem como reconciliar o grupo violentado com a comunidade, e também resolver os conflitos sociais em busca de uma não violência. (HERNÁNDEZ, 2002, p. 68-71) E como as violências que afetam as pessoas em situação de rua é de extensão ampliada, a reforma da visão que se confere tanto às primeiras quanto às segundas é medida urgente.

De fato, "o problema fundamental em relação aos direitos do homem, hoje, não é tanto o de justificá-los, mas o de protegê-los" (BOBBIO, 1992, p. 24), de modo que a segurança à população em situação de rua ainda é um projeto de concretização árdua. Todavia, o percurso é necessário e inevitável. Como obtempera J. A. Silva (1988, p. 91-92), a dignidade da pessoa humana pré-existe à criação constitucional, servindo o texto da Lei Fundamental de reconhecimento de sua existência e eminência, o que a eleva a valor supremo da ordem jurídica (fundamento da República Federativa do 
Brasil - artigo $1^{\circ}$, inciso III, da Constituição Federal), ou seja, estrutura todo o ordenamento constitucional e infraconstitucional, da democracia em si, da ordem política e social, inclusive. A dignidade da pessoa humana, por conseguinte, pressupõe que o direito fundamental individual, coletivo e social à segurança seja efetivamente consolidado em relação a todos, e, em especial, às pessoas em situação de rua.

\section{CONSIDERAÇÕES FINAIS}

Pretender a extinção para que se conquiste a amenização das violências cometidas contra as pessoas em situação de rua é ação que urge aflorar no Brasil. A desproteção social a que está submetida a população em situação de rua somente é agravada pelas violências que lhe são desferidas.

A naturalização das violências em relação às pessoas em situação de rua, que reflete a invisibilidade social incidente sobre as mesmas, contribui decisivamente para a reprodução e manutenção do estágio de violência. De rigor, logo, que se desnaturalize as diversas modalidades de violências cometidas contra a população em situação de rua para que a pressão social influa na consciência crítica do Poder Público para que a intervenção social seja efetivamente proativa, ultrapassando a concepção de políticas sociais de ínfima superação das violências.

Desvelando as violências e retirando a temática do ocultismo no que concerne às pessoas em situação de rua, como ora se faz, abre-se espaço ao diálogo para a inserção do direito fundamental à segurança como outro componente indispensável para a superação que requer urgência - das questões sociais supracomentadas. $\mathrm{O}$ Estado, omisso ou praticamente nulo na intervenção dirigida à segurança das pessoas em situação de rua, contribui (in)diretamente na manutenção da insegurança dessas pessoas.

Nesse diapasão, sem olvidar da busca pela emancipação das pessoas em situação de rua, é imperioso que se instrumentalizem meios contra as violências para que a sua segurança seja integralmente respeitada. E isso decorre, precipuamente, do próprio direito fundamental à segurança, porém também é inerente à dignidade da pessoa humana, fundamento da República Federativa do Brasil. 


\section{REFERÊNCIAS}

ALCANTARA, Stefania Carneiro de; ABREU, Desirée Pereira; FARIAS, Alessandra Araújo. Pessoas em situação de rua: das trajetórias de exclusão social aos processos emancipatórios de formação de consciência, identidade e sentimento de pertença. Revista Colombiana de Psicologia, Bogotá, v. 24, n. 1, pp. 129-143, ene./jun. 2015.

BENTHAM, Jeremy. O panóptico ou a casa de inspeção. Tradução de Tomaz Tadeu. In: TADEU, Tomaz (org.). O panóptico. 2. ed. Belo Horizonte: Autêntica, 2008. p. 13-87.

BOBBIO, Norberto. A era dos direitos. Tradução de Carlos Nelson Coutinho. Rio de Janeiro: Campus, 1992.

BONAVIDES, Paulo. Curso de direito constitucional. 15. ed. São Paulo, Malheiros, 2004.

BRASIL. Ministério do Desenvolvimento Social e Combate à Fome. Rua: Aprendendo a contar: Pesquisa Nacional sobre a população em situação de rua. Brasília: Ministério do Desenvolvimento Social e Combate à Fome, Secretaria de Avaliação e Gestão da Informação, Secretaria Nacional de Assistência Social, 2009.

BURSZTYN, Marcel. Da pobreza à miséria, da miséria à exclusão: o caso das populações de rua. In: __ (org.). No meio da rua: nômades, excluídos e viradores. Rio de Janeiro: Garamond, 2003. p. 27-55.

CABRAL JÚNIOR, Luciano Roberto Gulart; COSTA, José Ricardo Caetano. Barreiras à cidadania nas políticas sociais para a população em situação de rua. Revista Brasileira de Políticas Públicas, Brasília, v. 6, n. 2, 2016, p. 229-241.

DEMO, Pedro. Pobreza política. $5^{\text {a }}$ ed. Campinas: Autores Associados, 1996.

FLEURY, Sônia. Estado sem cidadãos: seguridade social na América Latina. Rio de Janeiro: Fiocruz, 1994.

FOUCAULT, Michel. Vigiar e Punir: nascimento da prisão. Tradução de Raquel Ramalhete. 20. ed. Petrópolis: Vozes, 1999.

HERNÁNDEZ, Tosca. Des-cubriendo la violencia. In: BRICEÑO-LEÓN, Roberto (comp.). Violencia, sociedad y justicia en América Latina. Buenos Aires: Clacso, 2002. p. 57-75.

LAKATOS, Eva Maria; MARCONI, Marina de Andrade. Metodologia do trabalho científico: procedimentos básicos, pesquisa bibliográfica, projeto 
e relatório, publicações e trabalhos científicos. 7. ed. São Paulo: Atlas, 2012.

LUFT, Celso Pedro. Minidicionário Luft. 20. ed. São Paulo: Ática, 2001.

MARCONDES FILHO, Ciro. Violência política. $3^{\mathrm{a}}$ ed. São Paulo: Moderna, 1990.

MELO, Cíntia de Freitas. População de rua: entre a exclusão e a justiça social. In: GRINOVER, Ada Pellegrini et. al. (orgs.). Direitos fundamentais das pessoas em situação de rua. 2. ed. Belo Horizonte: D’Plácido, 2016. p. 51-64.

MICHAUD, Yves. A violência. Tradução de L. Garcia. São Paulo: Ática, 1989.

MOREIRA NETO, Diogo de Figueiredo. Revisão doutrinária dos conceitos de ordem pública e segurança pública: uma análise sistêmica. Revista de Informação Legislativa, v. 25, n. 97, pp. 133-154, jan./mar. 1988.

MÜLLER, Friedrich. Quem é o povo? A questão fundamental da democracia. Tradução de Peter Naumann. 3. ed. São Paulo: Max Limonad, 2003.

ODALIA, Nilo. O que é violência. $6^{a}$ ed. São Paulo: Brasiliense, 2006.

PAUGAM, Serge. Elementos de comparação da pobreza e da exclusão na Europa, nos Estados Unidos e no Brasil. In: VÉRAS, Maura Pardini Bicudo (ed.). Por uma sociologia da exclusão social: o debate com Serge Paugam.. São Paulo: EDUC, 1999. p. 97-113.

SANTOS, Boaventura de Sousa. Poderá o direito ser emancipatório? Revista Crítica de Ciências Sociais, n. 65, pp. 3-76, mai. 2003.

SANTOS, José Vicente Tavares dos. A cidadania dilacerada. Revista Crítica de Ciências Sociais, n. 37, p. 131-148, jun. 1993.

SARLET, Ingo Wolfgang. A eficácia dos direitos fundamentais: uma teoria geral dos direitos fundamentais na perspectiva constitucional. $10^{\mathrm{a}}$ ed. rev. atual. e ampl. Porto Alegre: Livraria do Advogado, 2009.

SILVA, José Afonso da. A dignidade da pessoa humana como valor supremo da democracia. Revista de Direito Administrativo, Rio de Janeiro, v. 212, pp. 89-94, abr./jun. 1998.

Curso de direito constitucional positivo. 25 . ed. rev. e atual. São Paulo: Malheiros Editores, 2005.

SILVA, Maria Lucia Lopes da. Mudanças recentes no mundo do trabalho e o fenômeno da população em situação de rua no Brasil 1995 - 2005. Dissertação - Universidade de Brasília, Brasília, 2006. 
SIMÕES JÚNIOR, José Geraldo. Moradores de rua. São Paulo: Pólis, 1992.

VALENCIO, Norma Felicidade Lopes da Silva et al. Pessoas em situação de rua no Brasil: Estigmatização, desfiliação e desterritorialização. Revista Brasileira de Sociologia da Emoção, v. 7, n. 21, pp. 556-605, dez. 2008. 